\title{
Human C-reactive protein and the metabolic syndrome
}

\author{
Sridevi Devaraj, Uma Singh, and Ishwarlal Jialal \\ Laboratory for Atherosclerosis and Metabolic Research, University of California Davis Medical \\ Center, Sacramento, California, and VA Medical Center, Mather, USA
}

\begin{abstract}
Purpose of review-Low-grade inflammation is characteristic of the metabolic syndrome (MetS). C-reactive protein (CRP), the best characterized biomarker of inflammation, is also an independent predictor of future cardiovascular events. The purpose of this review is to outline the role of inflammation and high sensitivity CRP in the MetS.
\end{abstract}

\begin{abstract}
Recent findings-Emerging laboratory and epidemiological data now link inflammation and high sensitivity CRP to insulin resistance and adiposity and other features of MetS. Furthermore, in large prospective studies, increased high sensitivity CRP levels in MetS confer greater cardiovascular risk. CRP has been shown to impair insulin signaling and contributes to atherothrombosis.
\end{abstract}

Summary-Thus, although a high CRP level predisposes to increased cardiovascular risk in MetS, future investigation is warranted on the in-vivo role of CRP in mediating vascular effects and resulting in increased cardiovascular events in MetS patients.

\section{Keywords}

C-reactive protein; inflammation; metabolic syndrome; vascular cells

\section{Introduction}

Metabolic syndrome (MetS) comprises a cluster of abnormalities with insulin resistance and adiposity as central features [1-3]. Five diagnostic criteria have been identified by the ATPIII, and the presence of any three features [central obesity, dyslipidemia (high triglycerides, low HDL), hypertension, and impaired fasting glucose (IFG)] is considered sufficient to diagnose the syndrome [4]. Twenty-four percent of the US adults have the MetS, and the prevalence increases with age (44\% at age of 60 years) [5].

\section{The metabolic syndrome and cardiovascular disease}

Patients with MetS have an increased burden of cardiovascular disease (CVD) [6-8]. In the Kuopio Ischemic Heart Disease study, Lakka et al. [6] convincingly showed that men with the MetS, even in the absence of baseline coronary artery disease (CAD) or diabetes, had a significantly increased mortality from CAD. In the Botnia Study, the MetS was defined as the presence of at least two of the following risk factors: obesity, hypertension, dyslipidemia, or microalbuminuria. Cardiovascular mortality was assessed in 3606 patients with a median follow-up of 6.9 years. In women and men, respectively, the MetS was seen in 10 and $15 \%$ of patients with normal glucose tolerance (NGT), 42 and $64 \%$ of those with

Correspondence to Ishwarlal Jialal, Laboratory for Atherosclerosis and Metabolic Research, University of California Davis Medical Center, 4635 2nd Avenue, Research 1 Building, Room 3000, Sacramento, CA 95817, USA, Tel: +1 916734 6590; fax: +1 916734 6593; ishwarlal.jialal@ucdmc.ucdavis.edu. 
IFG/impaired glucose tolerance (IGT), and 78 and $84 \%$ of those with type 2 diabetes mellitus (T2DM). The risk for coronary heart disease (CHD) and stroke was increased threefold in patients with MetS $(P<0.001)$, and cardiovascular mortality was increased six-fold (12.0 versus $2.2 \%, P<0.001$ ) [6-8]. Using data from Third National Health and Nutrition Examination Survey (NHANES III), Alexander et al. [7] also reported that the MetS is very common, with $44 \%$ of the US population over 50 years of age meeting the ATPIII criteria. Those with MetS without diabetes had higher CHD prevalence (13.9\%), and those with both MetS and diabetes had the highest prevalence of CHD (19.2\%) compared with those with neither. MetS was a significant univariate predictor of prevalent CHD. The Hoorn Study examined 615 men and 749 women aged 50-75 years, without diabetes or a history of CVD at baseline and reported that the National Cholesterol Education Program (NCEP)-ATPIII definition of MetS was associated with about a two-fold increase in age-adjusted risk of fatal CVD in men and nonfatal CVD in women [6-8]. The lower but significant risks were also obtained using the WHO, American College of Endocrinology (ACE), and European Group on Insulin Resistance (EGIR) definitions of MetS. Also, Ford [5] using the modified NCEPATPIII criteria on the NHANES cohort, also reported significantly increased prevalence of MetS in the US population.

\section{The metabolic syndrome and diabetes}

Apart from the effect on cardiovascular morbidity and mortality, the components of the MetS have been associated with diabetes. Factor analysis was used to identify the components of the MetS on 1918 Pima Indians [9]. Insulin resistance factor was strongly associated with diabetes in a 4-year follow-up. Also, the body size and the lipid factor predicted diabetes, whereas the blood pressure (BP) factor did not.

In the West of Scotland Coronary Prevention Study (WOSCOPS) [10], MetS increased the risk for $\mathrm{CHD}$ event and for diabetes. MetS continued to predict $\mathrm{CHD}$ events in a multivariate model incorporating conventional risk factors. Patients with four or five features of the syndrome had a 3.7-fold increase in risk for CHD and a 24.5-fold increased risk for diabetes compared with those with none. The Prospective Cardiovascular Münster (PROCAM) study [11] also reported a 2.3-fold increased incidence of CVD in patients with the MetS, and these effects persisted after adjustment for conventional risk factors.

Thus, overall MetS, per se, confers an increased propensity to both diabetes and CVD. Although individual components of MetS independently contribute to increased cardiovascular risk, in concert, they do not explain the increased propensity of vascular disease in patients with MetS, and the precise mechanisms for this increased propensity remain to be elucidated. Inflammation is pivotal in all phases of atherosclerosis from foam cell formation to culmination in acute coronary syndromes. Also, several lines of evidence demonstrate that diabetes is a proinflammatory state. It appears that low-grade chronic inflammation is a central feature of MetS and could contribute to increased risks of both CVD and diabetes in MetS.

\section{Inflammation, high sensitivity C-reactive protein, and increased cardiovascular risk in metabolic syndrome}

Circulating levels of several inflammatory biomarkers have been studied to assess their value in predicting CVD. The best characterized and well standardized biomarker of inflammation is C-reactive protein (CRP). Numerous studies [12] have now confirmed that CRP levels are elevated in patients with the MetS. Furthermore, it has been proposed that high sensitivity CRP (hsCRP) be added as a clinical criterion for MetS and for creation of an hsCRP-modified CHD risk score [12]. 
Evidence supporting the hypothesis that elevated CRP levels contributes to increased cardiovascular risk is now available from at least six major prospective studies, these include the Physicians' Health Study (PHS), Women's Health Study (WHS), Atherosclerosis Risk in Communities (ARIC), Air Force/Texas Coronary Atherosclerosis Prevention Study (AFCAPS/TexCAPS) in the United States and Monitoring Trends and Determinants in Cardiovascular Disease (MONICA) and Reykjavik studies from Europe [13-18]. Additionally, with regards to MetS, Yudkin et al. [19] in 107 nondiabetic patients conducted $Z$-score analyses and found a very significant correlation between inflammatory markers and several features of the MetS. CRP levels were shown to be strongly associated with insulin resistance calculated from the homeostatic model assessment (HOMA) model, BP, low HDL, triglycerides, and to levels of the proinflammatory cytokines, IL-6 and tumor necrosis factor (TNF). BMI and insulin resistance were the strongest determinants of the inflammatory state. There is a linear relationship between the number of metabolic features and increasing levels of hsCRP. Furthermore, Festa et al. [20] in the Insulin Resistance and Atherosclerosis Study (IRAS) showed that hsCRP was positively correlated with BMI, waist circumference, BP, triglycerides, cholesterol, LDL cholesterol, plasma glucose, and fasting insulin, and inversely correlated with HDL cholesterol and insulin sensitivity index. The strongest associations are observed between CRP levels, central adiposity, and insulin resistance. The largest study to date that examined the association between inflammation and the MetS was the NHANES III study [21]. In a representative sample of the US population (8570 participants $>20$ years of age), patients with the MetS, defined using ATPIII criteria, were more likely than those without the syndrome to have elevated levels of markers of inflammation such as CRP, fibrinogen as well as leukocyte count. Thus, there appears to be a clear relationship between the numbers of metabolic features and increasing hsCRP levels. In addition, we have shown that CRP levels were equivalent to the ratio of high-molecular weight (HMW) adiponectin:CRP in predicting MetS using receiver operating characteristic (ROC) analyses [22 $]$. Furthermore, Sugiura et al. [23] have also reported that leptin (positively) and adiponectin (negatively) were independently associated with CRP. It is also worthwhile noting that adiponectin decreased CRP synthesis and secretion, whereas leptin increases CRP secretion. Thus, MetS is a proinflammatory state characterized by increased CRP levels.

Ridker et al. [24] evaluated in a large-scale population cohort of the WHS, the potential interrelationships between CRP, the MetS, and incident cardiovascular events (CVEs). In the 8-year prospective follow-up of 14719 women in the WHS, an hsCRP of more than 3 $\mathrm{mg} / \mathrm{l}$ in patients with MetS predicted a greater age-adjusted relative risk (RR) for future CVE. Furthermore, they reported that at all levels of severity of the MetS, CRP added prognostic information with regard to subsequent risk of incident CVE and was additive to the Framingham risk score. Thus, it has been proposed that hsCRP be added as a clinical criterion for MetS and for creation of an hsCRP-modified CHD risk score [25].

In the WOSCOPS, in which 6447 men were followed for 4.9 years, an hsCRP level of more than $3 \mathrm{mg} / \mathrm{l}$ predicted greater cardiovascular risk in patients with the MetS in a multivariate model [26]. In the Framingham Offspring Study [13], both CRP and MetS were independent predictors of new CVEs but were not additive. In an Italian study, patients with MetS and CRP of more than $3 \mathrm{mg} / \mathrm{l}$ had higher incidence of both carotid and CAD. Pischon et al. [27] showed in the Nurses' Health Study and Health Professionals Follow-up Study that although MetS was a strong predictor of CHD in both men and women, however, CRP was additive in men only. It should be emphasized that in this study, a modified definition of MetS was used, as waist circumference, BP, and glucose were not available at baseline. In a smaller Japanese Study [28] of 461 patients with acute myocardial infarction (AMI), CRP levels were additive to MetS in predicting future major adverse cardiac events (MACEs). Furthermore, recent investigation relating increased CRP levels and MetS in 1044 older 
( $\geq 65$ years of age) individuals has also led to the conclusion that MetS is associated with low-grade systemic inflammation, and the association is mainly supported by a strong independent correlation between waist circumference and high hsCRP levels. Collectively, all these studies support the hypothesis that an increased CRP in the setting of MetS confers an increased risk of future CVEs.

Additionally, a genome-wide association study [24] has been performed recently among 6345 apparently healthy women in which 336108 single-nucleotide polymorphisms (SNPs) were evaluated as potential determinants of plasma CRP concentration. Overall, seven loci that associate with plasma CRP at levels achieving genome-wide statistical significance were found. Two of these loci [glucokinase hexokinase 4 regulator (GCKR) and hepatic nuclear factor 1 homeobox A (HNF1A)] are suspected or known to be associated with maturity-onset diabetes of the young, one is a gene-desert region on 12q23.2, and the remaining four loci are in or near the leptin receptor protein gene, the apolipoprotein $\mathrm{E}$ gene, the IL-6 receptor protein gene, or the $C R P$ gene itself. The protein products of six of these seven loci are directly involved in MetS, insulin resistance, $\beta$ cell function, weight homeostasis, and/or premature atherothrombosis. Thus, it is concluded that a common variation in several genes involved in metabolic and inflammatory regulation have significant effects on CRP levels, consistent with CRP's identification as a useful biomarker of risk for incident vascular disease and diabetes. All these findings have sparked increased discussion about the formal addition of hsCRP to the criteria of MetS. In addition to the prognostic information that hsCRP evaluation might add to the current definition of MetS, there are several other practical appeals of hsCRP measurement. First, hsCRP is strongly associated with components of MetS that are difficult to measure in routine clinical practice, such as impaired fibrinolysis and insulin resistance [19,20]. Also, the widespread availability of commercial assays now for hsCRP has made its measurement simple and inexpensive. In addition, hsCRP does not display diurnal variation and demonstrates longterm stability comparable with cholesterol, and it can be reliably evaluated with a single nonfasting measurement $[29,30]$. The addition of hsCRP measurement to our present diagnosis of the MetS may significantly improve the early detection of risk for future diabetes and CVE in individuals. Overall, it appears that in patients with MetS, an elevated CRP confers a greater risk for CVE by its action on vascular cells such as activation of monocytes and induction of endothelial cell dysfunction.

\section{C-reactive protein, the metabolic syndrome, and type 2 diabetes mellitus}

The MetS is a constellation of risk factors that predispose to increased cardiovascular risk and morbidity and is a common disorder affecting $35 \%$ of the US adults based on data from the NHANES III [31]. MetS confers an increased propensity to diabetes and CVD. All of these characteristics are also associated with elevated levels of CRP. Among participants without diabetes in the WHS, high CRP levels and BMI were the only independent correlates of fasting insulin level modeled as a continuous dependent variable. After adjustment for BMI and other risk factors for diabetes, the RR for elevated fasting insulin ( $\geq 51.6 \mathrm{pmol} / \mathrm{l})$ increased with tertile of hsCRP [32]. Also, in the WHS, the addition of hsCRP to the traditional definition of the MetS provided the best predictive algorithm. A similar pattern of results was observed in the WOSCOPS [26], which followed 6447 middleaged men for 5 years. hsCRP, coded as at least $3 \mathrm{mg} / \mathrm{l}$ versus less than $3 \mathrm{mg} / \mathrm{l}$, was strongly predictive of incident CHD after stratification by MetS status. Among men in the 'low-CRP/ metabolic syndrome absent', 'high-CRP/metabolic syndrome absent', 'low-CRP/metabolic syndrome present', and 'high-CRP/metabolic syndrome present' groups, the RRs for incident CHD were 1.0 (referent), 1.6 [95\% confidence interval (CI), 1.3-2.1], 1.6 (95\% CI, 1.2-2.1), and 2.75 (95\% CI, 2.1-3.6), respectively. With regards to diabetes, numerous groups have demonstrated that diabetes is a proinflammatory state as evidenced by increased 
levels of circulating CRP. However, it is not clear whether the increased CRP in diabetes is a causative factor in inducing inflammation and complications of diabetes.

\section{C-reactive protein and development of diabetes}

Elevated hsCRP levels have also been implicated in the development of T2DM, a powerful risk factor for CVD. Prospective studies [5,8,12,20,33-36] have found strong, graded relations between hsCRP and incident diabetes, which in many instances persisted after adjustment for BMI and other covariates. In the WHS, women in the top quartile of the hsCRP distribution were more than four times as likely to develop diabetes than were women in the bottom quartile during 4 years of follow-up and this was also reported by Festa et al. [20] in the IRAS study population. The IRAS found a linear increase in mean log hsCRP values according to the number of metabolic disorders present in each of 1008 patients without diabetes or CAD. Also, in the Nurses' Health study, hsCRP was a strong predictor of development of diabetes. This has been confirmed now by at least 10 prospective studies. These observations suggest that CRP is expressed in advance of overt diabetes and may be an integral component of prediabetic insulin resistance.

\section{C-reactive protein and insulin signaling}

Two recent reports provide provocative evidence that CRP may impair insulin signaling [37,38]. Xu et al. [37] show that recombinant CRP attenuates insulin signaling through the regulation of spleen tyrosine kinase (Syk) on small G-protein $\rho$ A, jun N-terminal kinase (JNK) mitogen-activated protein kinase (MAPK), insulin receptor substrate-1 (IRS-1), and endothelial nitric oxide synthase (eNOS) in vascular endothelial cells. Recombinant CRP suppressed insulin-induced nitric oxide production, inhibited the phosphorylation of Akt and eNOS, and stimulated the phosphorylation of IRS-1 at the Ser307 site in a dose-dependent manner. These events were blocked by treatment with an inhibitor of $\rho \mathrm{A}$-dependent kinase Y27632, or an inhibitor of JNK SP600125, or the transfection of dominant negative $\rho \mathrm{A}$ cDNA. Also, antibody to CD32 partially blocked the recombinant CRP-induced phosphorylation of JNK and IRS-1 and restored, to a certain extent, the insulin-stimulated phosphorylation of Akt. D'Alessandris et al. [38] determined the effects of human recombinant CRP (hrCRP) on insulin signaling involved in glucose transport in L6 myotubes. Their data suggest that hrCRP may cause insulin resistance by increasing IRS-1 phosphorylation at Ser307 and Ser612 via JNK and extracellular signal-regulated kinases 1 and 2 (ERK1/2), respectively, leading to impaired insulin-stimulated glucose uptake, glucose transporter 4 (GLUT4) translocation, and glycogen synthesis mediated by the IRS-1/phosphoinositide-3 kinase (PI-3K)/Akt/glycogen synthase kinase 3 (GSK-3) pathway.

Thus, these provocative evidences of CRP levels being associated with increased CVE and diabetes confirm evidence from numerous laboratories delineating the effects of CRP on atherothrombosis in vivo and in vitro as reviewed previously [39]. Also, a recent study [40*0] examined the intravascular kinetics of CRP and its relationship to features of MetS. The production rate of CRP that mirrored plasma CRP levels was shown to be significantly correlated to features of MetS such as waist, high triglycerides, low HDL, and also to biomarkers of inflammation and adipose tissue biology such as high IL-6 and low adiponectin. Furthermore, CRP is also synthesized in the adipose tissue [41] and may be present in excessive quantities in patients with abdominal obesity, eventually resulting in insulin resistance and diabetes. 


\section{Experimental evidence linking C-reactive protein to its effects on vascular cells}

CRP exerts proatherogenic effects on vascular cells such as endothelial cells, smooth muscle cells, and monocyte-macrophages.

\section{C-reactive protein, endothelial dysfunction, and metabolic syndrome}

Endothelial dysfunction is now recognized to play a critical role in the initiation and progression of atherosclerotic vascular disease [42-44]. Furthermore, endothelial function assessment by brachial flow-mediated dilatation is a surrogate marker of cardiovascular risk $[45,46]$ and has been shown to be decreased in MetS [47-52]. It is well established that the individual components of the MetS are related to endothelial dysfunction. Previous studies [53,54] have shown that obesity, low HDL cholesterol, IGT, hypertriglyceridemia, and hypertension are associated with decreased endothelium-dependent vasodilatation. Also, insulin resistance is associated with endothelial dysfunction [55,56].

An impressive amount of data now implicates CRP in inducing endothelial cell activation and dysfunction in vitro as well as in vivo [57-61]. Several observations demonstrated that CRP levels correlated inversely with endothelial vasoreactivity in vivo $[62,63]$. The most compelling data implicating CRP as a determinant of endothelial dysfunction were studies $[64,65]$ demonstrating that human CRP reduced basal and stimulated nitric oxide release from arterial and venous endothelial cells. Our group has explored various mechanistic events involved in CRP-mediated eNOS inhibition and documented that increased NADPH oxidase activation and guanosine triphosphate cyclohydrolase 1 (GTPCH1) downregulation are associated with CRP-mediated eNOS uncoupling in human aortic endothelial cells (HAECs) in vitro [66 $]$. In-vivo studies $[57,58,60-63]$ have shown that CRP impairs endothelial vasoreactivity and decreases eNOS activity. Guan et al. [67"*] showed that a single intravenous (i.v.) injection of adeno-associated virus (AAV) vector with CRP (AAVhsCRP) to male rats resulted in efficient and sustained expression of CRP in the liver and other tissues and an increase in serum CRP to $15 \mu \mathrm{g} / \mathrm{ml}$ at 2 and 4 months. This was associated with an increase in systolic and mean arterial pressure. Also, the authors go on to show impaired endothelium-dependent vasoreactivity in the AAV-hsCRP versus AAVgreen fluorescent protein (GFP) administered control rats. Previously, we have shown [59] that CRP inhibits prostacyclin synthase resulting in decreased prostacyclin, a potent vasodilator. Thus, CRP, by inducing endothelial dysfunction, could put patients with MetS at further risk for hypertension.

Patients with MetS are in a procoagulant state as evidenced by increased circulating plasminogen activator inhibitor-1 (PAI-1). We have shown that CRP induces PAI-1 and decreases tissue plasminogen activator (tPA) in endothelial cells $[68,69]$. CRP appears to induce PAI-1 antigen and activity via upregulation of nuclear factor kappa-light-chainenhancer of activated B cells (NF-kB) activities [70].

\section{C-reactive protein, monocytes-macrophages, and metabolic syndrome}

The proinflammatory effects of CRP that have been documented in monocyte-macrophages include induction of tissue factor, proinflammatory cytokines, ROS, chemokine receptor 2 (CCR2), matrix metalloproteinases (MMPs) release, CD11b expression, and oxidized LDL uptake as well as inhibition of cholesterol efflux and lipopolysaccharide (LPS)-induced IL-10 release [71-77,78 $]$. Another important in-vivo demonstration made recently is from our group on the induction of myeloperoxidase (MPO) activity in macrophages by CRP administration [79]. 
Several lines of experimental evidence support monocyte chemotactic protein-1's (MCP-1) role in atherogenesis, insulin resistance, and adipose tissue-mediated inflammation. Also, CRP has been reported to induce MCP-1 in endothelial cells and its receptor, CCR2 on monocytes [73]. Furthermore, Esposito et al. [80] have reported that in both obese and nonobese women, IL-10 levels were significantly lower in women with MetS. In this regard, we have reported that CRP inhibits LPS-induced IL-10 release from human monocytesderived macrophages (HMDM) [81].

Oxidative stress, mainly superoxide, plays a critical role in the pathogenesis of MetS parameters [82]. Fortuño et al. [83] have reported increased mononuclear cell (MNC) activation in MetS compared with controls. They also demonstrate increased superoxide, nitrotyrosine and oxidized LDL in MetS compared with controls, although MetS patients studied in this report were on various medications including statins (39\%) as well as oral hyperglycemics (21\%). Thus, there is an emergent need to study monocyte biology in drugnaïve MetS patients that has not been explored yet. Furthermore, CRP has been shown by numerous investigators including our group to result in increased superoxide production as a result of enhanced NADPH oxidase activity in endothelial cells as well as in human peripheral blood monocytes $\left[59,66^{\circ}, 72,78^{\circ}, 82\right]$. Also, in-situ hybridization revealed the presence of CRP mRNA that colocalized with p22phox, an essential component of NADPH oxidase [84]. We also demonstrated in Wistar rats that CRP stimulates superoxide production in macrophages via upregulation of NADPH oxidase [72].

Increased oxidized LDL in the vessel wall and circulation has been shown in patients with acute coronary syndrome and was associated with endothelial dysfunction and predicted CVE [85]. Furthermore, patients with MetS exhibit increased plasma oxidized LDL levels [86]. In addition, we recently showed that CRP promotes oxidized LDL uptake and cholesterol ester accumulation in Wistar rats $\left[7^{\circ}\right]$.

Patients with MetS are in a procoagulant state. Tissue factor is increased in morbidly obese persons with abnormal glucose tolerance compared with those with NGT [87]. Diamant $e t$ al. [87] also demonstrated increased tissue factor-containing microparticles in T2DM that correlated significantly with features of MetS in this population. In vivo, several lines of evidence indicate that CRP promotes procoagulant activity [39]. We have shown that CRP promotes tissue factor activity in vitro and in vivo in the rat model, and that it is via activation of ROS and NF- $\mathrm{kB}$ [72]. Very importantly, recent results from the justification for the use of statins in primary prevention: an intervention trial evaluating rosuvastatin (JUPITER) trial, especially in those patients with hsCRP more than $2 \mathrm{mg} / \mathrm{l}$ but no other risk factors $(n=6375)$, showed a significant reduction in CVE with rosuvastatin supporting that CRP appears to be an active participant in atherothrombosis [88*0].

NF- $\kappa \mathrm{B}$ is a pivotal transcription factor involved in the induction of specific proinflammatory genes [89]. Studies in animal models have demonstrated the importance of I- $\kappa-B$ kinase $b$ $(\mathrm{IKKb})$ in the pathogenesis of insulin resistance in obese and diabetic rodents. Recently, it has also been shown in humans that obesity is associated with an increase in NF- $\mathrm{kB}$ binding in the nucleus and a decrease in the inhibitory $\kappa \mathrm{B}$ in the $\mathrm{MNC}$, with increased mRNA for TNF [90], IL-6, macrophage inhibitory factor (MIF), and MMP-9, consistent with the proinflammatory state. Recently, we have shown that CRP induces NF- $\mathrm{BB}$ activity in rat macrophages in vivo $\left[72,78^{\circ}\right]$.

All these reports support the notion that CRP is an effector molecule able to induce a proatherogenic phenotype. Therapeutic lifestyle change is the cornerstone of therapy in patients with MetS. Weight loss and caloric restriction appear to decrease CRP levels and the inflammatory burden in MetS. Other strategies that have been employed to decrease the 
inflammatory burden in MetS include the use of statin therapy and thiazolidenediones. In patients with MetS, we have previously shown that in addition to LDL lowering, simvastatin therapy compared with placebo resulted in decreased hsCRP levels and NF- $\mathrm{KB}$ activity in MNCs, thereby decreasing the resulting inflammatory state of MetS [91].

\section{Conclusion}

Emerging laboratory and clinical evidences have provided strong relationship between CRP and various features of MetS. The addition of CRP to the present definition of the MetS may help identify patients at high risk for future diabetes and CVD. Further investigation is clearly needed not only to clarify the molecular role of CRP in the pathogenesis of MetS but also in shedding new light on to the role of CRP specifically in mediating vascular effects and conferring CVE in MetS patients with high CRP levels.

\section{Acknowledgments}

The study is supported by grants: National Institutes of Health (NIH) K24 AT 00596 and NIH HL 074360.

\section{References and recommended reading}

Papers of particular interest, published within the annual period of review, have been highlighted as:

- of special interest

•• of outstanding interest

Additional references related to this topic can also be found in the Current World Literature section in this issue (p. 245).

1. Reaven GM. The insulin resistance syndrome: definition and dietary approaches to treatment. Annu Rev Nutr 2005;25:391-406. [PubMed: 16011472]

2. Eckel RH, Grundy SM, Zimmet PZ. The metabolic syndrome. Lancet 2005;365:1415-1428. [PubMed: 15836891]

3. Haffner S, Cassells HB. Metabolic syndrome: a new risk factor of coronary heart disease? Diabetes Obes Metab 2003;5:359-370. [PubMed: 14617221]

4. Expert Panel on Detection, Evaluation, and Treatment of High Blood Cholesterol in Adults. Executive summary of the third report of the National Cholesterol Education Program (NCEP) Expert Panel on Detection, Evaluation, and Treatment of High Blood Cholesterol in Adults (Adult Treatment Panel III). JAMA 2001;285:2486-2497. [PubMed: 11368702]

5. Ford ES. Prevalence of the metabolic syndrome defined by the International Diabetes Federation among adults in the US. Diabetes Care 2005;28:2745-2749. [PubMed: 16249550]

6. Lakka HM, Laaksonen DE, Lakka TA, et al. The metabolic syndrome and total and cardiovascular disease mortality in middle-aged men. JAMA 2002;288:2709-2716. [PubMed: 12460094]

7. Alexander CM, Landsman PB, Teutsch SM, Haffner SM. Third National Health and Nutrition Examination Survey (NHANES III). National Cholesterol Education Program (NCEP). NCEPdefined metabolic syndrome, diabetes, and prevalence of coronary heart disease among NHANES III participants age 50 years and older. Diabetes 2003;52:1210-1214. [PubMed: 12716754]

8. Devaraj S, Rosenson RS, Jialal I. Metabolic syndrome: an appraisal of the pro-inflammatory and procoagulant status. Endocrinol Metab Clin North Am 2004;33:431-453. [PubMed: 15158528]

9. Hanson RL, Imperatore G, Bennett PH, Knowler WC. Components of the 'metabolic syndrome' and incidence of type 2 diabetes. Diabetes 2002;51:3120-3127. [PubMed: 12351457]

10. Freeman D, Norrie J, Sattar N, et al. Pravastatin and the development of diabetes mellitus: evidence for a protective treatment effect in the West of Scotland Coronary Prevention Study. Circulation 2001;103:357-362. [PubMed: 11157685] 
11. Assmann G, Nofer JR, Schulte H. Cardiovascular risk assessment in metabolic syndrome: view from PROCAM. Endocrinol Metab Clin North Am 2004;33:377-392. [PubMed: 15158524]

12. Ridker PM, Hennekens CH, Buring JE, Rifai N. C-reactive protein and other markers of inflammation in the prediction of cardiovascular disease in women. N Engl J Med 2000;342:836843. [PubMed: 10733371]

13. Ridker PM, Glynn RJ, Hennekens CH. C-reactive protein adds to the predictive value of total and HDL cholesterol in determining risk of first myocardial infarction. Circulation 1998;97:20072011. [PubMed: 9610529]

14. Ridker PM, Buring JE, Cook NR, Rifai N. C-reactive protein, the metabolic syndrome, and risk of incident cardiovascular events: an 8-year follow-up of 14719 initially healthy American women. Circulation 2003;107:391-397. [PubMed: 12551861]

15. Ballantyne CM, Hoogeveen RC, Bang H, et al. Lipoprotein-associated phospholipase A2, highsensitivity C-reactive protein, and risk for incident ischemic stroke in middle-aged men and women in the Atherosclerosis Risk in Communities (ARIC) study. Arch Intern Med 2005;165:2479-2484. [PubMed: 16314544]

16. Downs JR, Clearfield M, Weis S, et al. Primary prevention of acute coronary events with lovastatin in men and women with average cholesterol levels: results of AFCAPS/TexCAPS. Air Force/ Texas Coronary Atherosclerosis Prevention Study. JAMA 1998;279:1615-1622. [PubMed: 9613910]

17. Koenig W, Khuseyinova N, Baumert J, Meisinger C. Prospective study of high-sensitivity Creactive protein as a determinant of mortality: results from the MONICA/KORA Augsburg Cohort Study, 1984-1998. Clin Chem 2008;54:335-342. [PubMed: 18156284]

18. Eiriksdottir G, Aspelund T, Bjarnadottir K, et al. Apolipoprotein E genotype and statins affect CRP levels through independent and different mechanisms: AGES-Reykjavik Study. Atherosclerosis 2006;186:222-224. [PubMed: 16445917]

19. Yudkin JS, Juhan-Vague I, Hawe E, et al. The HIFMECH Study group. Low-grade inflammation may play a role in the etiology of the metabolic syndrome in patients with coronary heart disease: the HIFMECH study. Metabolism 2004;53:852-857. [PubMed: 15254876]

20. Festa A, D'Agostino R Jr, Howard G, et al. Chronic subclinical inflammation as part of the insulin resistance syndrome: the Insulin Resistance Atherosclerosis Study (IRAS). Circulation 2000;102:42-47. [PubMed: 10880413]

21. $\mathrm{Vu} \mathrm{JD}, \mathrm{Vu} J B$, Pio JR, et al. Impact of C-reactive protein on the likelihood of peripheral arterial disease in United States adults with the metabolic syndrome, diabetes mellitus, and preexisting cardiovascular disease. Am J Cardiol 2005;96:655-658. [PubMed: 16125489]

22. Devaraj S, Swarbrick MM, Singh U, et al. CRP and adiponectin and its oligomers in the metabolic syndrome: evaluation of new laboratory-based biomarkers. Am J Clin Pathol 2008;129:815-822. Compared with matched controls, this study shows that CRP is equivalent to adiponectin, its oligomers, in predicting the MetS. [PubMed: 18426744]

23. Sugiura K, Tamakoshi K, Yatsuya H, et al. Contribution of adipocytokines to low-grade inflammatory state as expressed by circulating C-reactive protein in Japanese men: comparison of leptin and adiponectin. Int J Cardiol 2008;130:159-164. [PubMed: 18495270]

24. Ridker PM, Pare G, Parker A, et al. Loci related to metabolic-syndrome pathways including LEPR, HNF1A, IL6R, and GCKR associate with plasma C-reactive protein: the Women's Genome Health Study. Am J Hum Genet 2008;82:1185-1192. [PubMed: 18439548]

25. Ridker PM, Wilson PW, Grundy SM. Should C-reactive protein be added to metabolic syndrome and to assessment of global cardiovascular risk? Circulation 2004;109:2818-2825. [PubMed: 15197153]

26. Freeman DJ, Norrie J, Caslake MJ, et al. West of Scotland Coronary Prevention Study. C-reactive protein is an independent predictor of risk for the development of diabetes in the West of Scotland Coronary Prevention Study. Diabetes 2002;51:1596-1600. [PubMed: 11978661]

27. Pischon T, Hu FB, Rexrode KM, et al. Inflammation, the metabolic syndrome, and risk of coronary heart disease in women and men. Atherosclerosis 2008;197:392-399. [PubMed: 17681508] 
28. Takeno M, Yasuda S, Otsuka Y, et al. Impact of metabolic syndrome on the long-term survival of patients with acute myocardial infarction: potential association with C-reactive protein. Circ J 2008;72:415-419. [PubMed: 18296838]

29. Gotto AM Jr. Role of C-reactive protein in coronary risk reduction: focus on primary prevention. Am J Cardiol 2007;99:718-725. [PubMed: 17317380]

30. de Ferranti SD, Rifai N. C-reactive protein: a nontraditional serum marker of cardiovascular risk. Cardiovasc Pathol 2007;16:14-21. [PubMed: 17218210]

31. Ford ES, Giles WH, Dietz WH. Prevalence of the metabolic syndrome among US adults: findings from the third National Health and Nutrition Examination Survey. JAMA 2002;287:356-359. [PubMed: 11790215]

32. Cook NR, Buring JE, Ridker PM. The effect of including C-reactive protein in cardiovascular risk prediction models for women. Ann Intern Med 2006;145:21-29. [PubMed: 16818925]

33. Jager A, van Hinsbergh VW, Kostense PJ, et al. von Willebrand factor, C-reactive protein, and 5year mortality in diabetic and nondiabetic subjects: the Hoorn Study. Arterioscler Thromb Vasc Biol 1999;19:3071-3078. [PubMed: 10591689]

34. Festa A, D’Agostino R Jr, Tracy RP, et al. Insulin Resistance Atherosclerosis Study. Elevated levels of acute-phase proteins and plasminogen activator inhibitor-1 predict the development of type 2 diabetes: the insulin resistance atherosclerosis study. Diabetes 2002;51:1131-1137. [PubMed: 11916936]

35. Meier-Ewert HK, Ridker PM, Rifai N, et al. Absence of diurnal variation of C-reactive protein concentrations in healthy human subjects. Clin Chem 2001;47:426-430. [PubMed: 11238292]

36. Ockene IS, Matthews CE, Rifai N, et al. Variability and classification accuracy of serial highsensitivity C-reactive protein measurements in healthy adults. Clin Chem 2001;47:444-450. [PubMed: 11238295]

37. Xu JW, Morita I, Ikeda K, et al. C-reactive protein suppresses insulin signaling in endothelial cells: role of spleen tyrosine kinase. Mol Endocrinol 2007;21:564-573. [PubMed: 17095576]

38. D'Alessandris C, Lauro R, Presta I, et al. C-reactive protein induces phosphorylation of insulin receptor substrate-1 on Ser307 and Ser 612 in L6 myocytes, thereby impairing the insulin signaling pathway that promotes glucose transport. Diabetologia 2007;50:840-849. [PubMed: 17279354]

39. Verma S, Devaraj S, Jialal I. Is C-reactive protein an innocent bystander or proatherogenic culprit? C-reactive protein promotes atherothrombosis. Circulation 2006;113:2135-2150. [PubMed: 16671184]

40••. Mauger JF, Lévesque J, Paradis ME, et al. Intravascular kinetics of C-reactive protein and their relationships with features of the metabolic syndrome. J Clin Endocrinol Metab 2008;93:31586443. This study shows that the production rate of CRP is the main determinant of CRP levels and is significantly associated with features of MetS as well as adipose-derived cytokines, IL-6, and adiponectin. [PubMed: 18492753]

41. Ouchi N, Kihara S, Funahashi T, et al. Reciprocal association of C-reactive protein with adiponectin in blood stream and adipose tissue. Circulation 2003;107:671-674. [PubMed: 12578865]

42. Al-Qaisi M, Kharbanda RK, Mittal TK, et al. Measurement of endothelial function and its clinical utility for cardiovascular risk. Vasc Health Risk Manag 2008;4:647-652. [PubMed: 18827914]

43. Lamon BD, Hajjar DP. Inflammation at the molecular interface of atherogenesis: an anthropological journey. Am J Pathol 2008;173:1253-1264. [PubMed: 18948435]

44. Bakker W, Eringa EC, Sipkema P, et al. Endothelial dysfunction and diabetes: roles of hyperglycemia, impaired insulin signaling and obesity. Cell Tissue Res 2009;335:165-189. [PubMed: 18941783]

45. Corretti MC, Anderson TJ, Benjamin EJ, et al. International Brachial Artery Reactivity Task Force. Guidelines for the ultrasound assessment of endothelial-dependent flow-mediated vasodilation of the brachial artery: a report of the International Brachial Artery Reactivity Task Force. J Am Coll Cardiol 2002;39:257-265. [PubMed: 11788217]

46. Vita JA, Keaney JF Jr. Endothelial function: a barometer for cardiovascular risk? Circulation 2002;106:640-642. [PubMed: 12163419] 
47. Caballero AE. Endothelial dysfunction in obesity and insulin resistance: a road to diabetes and heart disease. Obes Res 2003;11:1278-1289. [PubMed: 14627747]

48. Shankar SS, Steinberg HO. Obesity and endothelial dysfunction. Semin Vasc Med 2005;5:56-64. [PubMed: 15968581]

49. Hsueh WA, Quinones MJ. Role of endothelial dysfunction in insulin resistance. Am J Cardiol 2003;92:10J-17J.

50. Suzuki T, Hirata K, Elkind MS, et al. Metabolic syndrome, endothelial dysfunction, and risk of cardiovascular events: the Northern Manhattan Study (NOMAs). Am Heart J 2008;156:405-410. [PubMed: 18657678]

51. Hamburg NM, Larson MG, Vita JA, et al. Metabolic syndrome, insulin resistance, and brachial artery vasodilator function in Framingham offspring participants without clinical evidence of cardiovascular disease. Am J Cardiol 2008;101:82-88. [PubMed: 18157970]

52. Melikian N, Chowienczyk P, MacCarthy PA, et al. Determinants of endothelial function in asymptomatic subjects with and without the metabolic syndrome. Atherosclerosis 2008;197:375382. [PubMed: 17651741]

53. Rodriguez CJ, Miyake Y, Grahame-Clarke C, et al. Relation of plasma glucose and endothelial function in a population-based multiethnic sample of subjects without diabetes mellitus. Am J Cardiol 2005;96:1273-1277. [PubMed: 16253596]

54. Brook RD, Bard RL, Rubenfire M, et al. Usefulness of visceral obesity (waist/hip ratio) in predicting vascular endothelial function in healthy overweight adults. Am J Cardiol 2001;88:1264-1269. [PubMed: 11728354]

55. Wheatcroft SB, Shah AM, Li JM, et al. Preserved glucoregulation but attenuation of the vascular actions of insulin in mice heterozygous for knockout of the insulin receptor. Diabetes 2004;53:2645-2652. [PubMed: 15448096]

56. Steinberg HO, Chaker H, Leaming R, et al. Obesity/insulin resistance is associated with endothelial dysfunction. Implications for the syndrome of insulin resistance. J Clin Invest 1996;97:2601-2610. [PubMed: 8647954]

57. Teoh H, Quan A, Lovren F, et al. Impaired endothelial function in C-reactive protein overexpressing mice. Atherosclerosis 2008;201:318-325. [PubMed: 18433756]

58. Grad E, Golomb M, Mor-Yosef I, et al. Transgenic expression of human C-reactive protein suppresses endothelial nitric oxide synthase expression and bioactivity after vascular injury. Am J Physiol Heart Circ Physiol 2007;293:H489-H495. [PubMed: 17369452]

59. Venugopal SK, Devaraj S, Jialal I. C-reactive protein decreases prostacyclin release from human aortic endothelial cells. Circulation 2003;108:1676-1678. [PubMed: 14504187]

60. Schwartz R, Osborne-Lawrence S, Hahner L, et al. C-reactive protein down-regulates endothelial NO synthase and attenuates reendothelialization in vivo in mice. Circ Res 2007;100:1452-1459. [PubMed: 17446434]

61. Fichtlscherer S, Breuer S, Schächinger V, et al. C-reactive protein levels determine systemic nitric oxide bioavailability in patients with coronary artery disease. Eur Heart J 2004;25:1412-1428. [PubMed: 15321699]

62. Fichtlscherer S, Rosenberger G, Walter DH, et al. Elevated C-reactive protein levels and impaired endothelial vasoreactivity in patients with coronary artery disease. Circulation 2000;102:1000 1006. [PubMed: 10961964]

63. Cleland SJ, Sattar N, Petrie JR, et al. Endothelial dysfunction as a possible link between C-reactive protein levels and cardiovascular disease. Clin Sci 2000;98:531-535. [PubMed: 10781383]

64. Venugopal SK, Devaraj S, Yuhanna I, et al. Demonstration that C-reactive protein decreases eNOS expression and bioactivity in human aortic endothelial cells. Circulation 2002;106:1439-1441. [PubMed: 12234944]

65. Verma S, Wang CH, Li SH, et al. A self-fulfilling prophecy: C-reactive protein attenuates nitric oxide production and inhibits angiogenesis. Circulation 2002;106:913-919. [PubMed: 12186793]

66•. Singh U, Devaraj S, Vasquez-Vivar J, Jialal I. C-reactive protein decreases endothelial nitric oxide synthase activity via uncoupling. J Mol Cell Cardiol 2007;43:780-791. An important study that describes mechanisms by which CRP increases oxidative stress, resulting in uncoupling of 
eNOS and reduced eNOS bioactivity, possibly explaining its role in causing endothelial dysfunction. [PubMed: 17942113]

67••. Guan H, Wang P, Rutai H, et al. Adeno-associated virus-mediated human C-reactive protein gene delivery causes endothelial dysfunction and hypertension in rats. Clin Chem 2009;55:274-284. An in-vivo demonstration that administration of CRP results in endothelial dysfunction and hypertension. [PubMed: 19056836]

68. Devaraj S, Xu DY, Jialal I. C-reactive protein increases plasminogen activator inhibitor-1 expression and activity in human aortic endothelial cells: implications for the metabolic syndrome and atherothrombosis. Circulation 2003;107:398-404. [PubMed: 12551862]

69. Singh U, Devaraj S, Jialal I. C-reactive protein decreases tissue plasminogen activator activity in human aortic endothelial cells: evidence that $\mathrm{C}$-reactive protein is a procoagulant. Arterioscler Thromb Vasc Biol 2005;25:2216-2221. [PubMed: 16123325]

70. Nakakuki T, Ito M, Iwasaki H, et al. Rho/Rho-kinase pathway contributes to C-reactive proteininduced plasminogen activator inhibitor-1 expression in endothelial cells. Arterioscler Thromb Vasc Biol 2005;25:2088-2093. [PubMed: 16123329]

71. Cermak J, Key NS, Bach RR, et al. C-reactive protein induces human peripheral blood monocytes to synthesize tissue factor. Blood 1993;82:513-520. [PubMed: 8329706]

72. Devaraj S, Dasu MR, Singh U, et al. C-reactive protein stimulates superoxide anion release and tissue factor activity in vivo. Atherosclerosis 2009;203:67-74. [PubMed: 18621373]

73. Han KH, Hong KH, Park JH, et al. C-reactive protein promotes monocyte chemoattractant protein-1-mediated chemotaxis through upregulating $\mathrm{CC}$ chemokine receptor 2 expression in human monocytes. Circulation 2004;109:2566-2571. [PubMed: 15136507]

74. Williams TN, Zhang CX, Game BA, et al. C-reactive protein stimulates MMP-1 expression in U937 histiocytes through Fc[gamma]RII and extracellular signal-regulated kinase pathway: an implication of CRP involvement in plaque destabilization. Arterioscler Thromb Vasc Biol 2004;24:61-66. [PubMed: 14592848]

75. Woollard KJ, Fisch C, Newby R, et al. C-reactive protein mediates CD11b expression in monocytes through the nonreceptor tyrosine kinase, Syk, and calcium mobilization but not through cytosolic peroxides. Inflamm Res 2005;54:485-492. [PubMed: 16389569]

76. Chang MK, Binder CJ, Torzewski M, et al. C-reactive protein binds to both oxidized LDL and apoptotic cells through recognition of a common ligand: phosphorylcholine of oxidized phospholipids. Proc Natl Acad Sci U S A 2002;99:13043-13048. [PubMed: 12244213]

77. Wang X, Liao D, Bharadwaj U, et al. C-reactive protein inhibits cholesterol efflux from human macrophage-derived foam cells. Arterioscler Thromb Vasc Biol 2008;28:519-526. [PubMed: 18096828]

78•. Singh U, Dasu MR, Yancey PG, et al. Human C-reactive protein promotes oxidized low density lipoprotein uptake and matrix metalloproteinase-9 release in Wistar rats. J Lipid Res 2008;49:1015-1023. In this study, authors demonstrate in vivo that CRP induces oxidative stress and promotes cholesterol ester accumulation and foam cell formation. [PubMed: 18245817]

79. Singh U, Devaraj S, Jialal I. C-reactive protein stimulates myeloperoxidase release from polymorphonuclear cells and monocytes. Clin Chem 2009;55:361-364. [PubMed: 19074520]

80. Esposito K, Pontillo A, Giugliano F, et al. Association of low interleukin-10 levels with the metabolic syndrome in obese women. J Clin Endocrinol Metab 2003;88:1055-1058. [PubMed: 12629085]

81. Singh U, Devaraj S, Dasu MR, et al. C-reactive protein decreases interleukin-10 secretion in activated human monocyte-derived macrophages via inhibition of cyclic AMP production. Arterioscler Thromb Vasc Biol 2006;26:2469-2475. [PubMed: 16917108]

82. Keaney JF Jr, Larson MG, Vasan RS, et al. Obesity and systemic oxidative stress: clinical correlates of oxidative stress in the Framingham Study. Arterioscler Thromb Vasc Biol 2003;23:434-439. [PubMed: 12615693]

83. Fortuño A, San José G, Moreno MU, et al. Phagocytic NADPH oxidase overactivity underlies oxidative stress in metabolic syndrome. Diabetes 2006;55:209-215. [PubMed: 16380495] 
84. Kobayashi S, Inoue N, Ohashi Y, et al. Interaction of oxidative stress and inflammatory response in coronary plaque instability: important role of CRP. Arterioscler Thromb Vasc Biol 2003;23:1398-1404. [PubMed: 12805076]

85. Ehara S, Ueda M, Naruko T. Elevated levels of oxidized low-density lipoprotein show a positive relationship with the severity of acute coronary syndromes. Circulation 2001;103:1955-1960. [PubMed: 11306523]

86. Holvoet P, Kritchevsky SB, Tracy RP, et al. The metabolic syndrome, circulating oxidized LDL, and risk of myocardial infarction in well functioning elderly people in the health, aging, and body composition cohort. Diabetes 2004;53:1068-1073. [PubMed: 15047623]

87. Diamant M, Nieuwland R, Pablo RF, et al. Elevated numbers of tissue-factor exposing microparticles correlate with components of the metabolic syndrome in uncomplicated type 2 diabetes mellitus. Circulation 2002;106:2442-2447. [PubMed: 12417540]

$88 \bullet$. Ridker PM, Danielson E, Fonseca F, et al. Rosuvastatin to prevent vascular events in men and women with elevated C-reactive protein. N Engl J Med 2008;359:2195-2207. A pivotal primary prevention trial with rosuvastatin showing significant $37 \%$ reduction in CVEs. Although rosuvastatin reduced LDL cholesterol by $50 \%$, the reduction in CVEs in JUPITER was almost twice that predicted based on LDL-cholesterol reduction, and CRP levels were significantly reduced by $37 \%$. Most importantly, in those with no risk factors except a high CRP, there was an equivalent benefit supporting the hypothesis that CRP may mediate atherothrombosis. [PubMed: 18997196]

89. Barnes PJ, Karin M. Nuclear factor-kappaB: a pivotal transcription factor in chronic inflammatory diseases. N Engl J Med 1997;336:1066-1071. [PubMed: 9091804]

90. Ghanim H, Aljada A, Hofmeyer D, et al. Circulating mononuclear cells in the obese are in a proinflammatory state. Circulation 2004;110:1564-1571. [PubMed: 15364812]

91. Devaraj S, Chan E, Jialal I. Direct demonstration of an anti-inflammatory effect of simvastatin in subjects with the metabolic syndrome. J Clin Endocrinol Metab 2006;91:4489-4496. [PubMed: 16968805] 